\title{
Improving Reading Habits of Grade IV Students
}

\section{Nima Dorji ${ }^{*}$ and Gembo Rinzin ${ }^{2}$}

${ }^{1}$ Principal, Khandothang Primary School, Samtse, Bhutan

2Principal, Gomtu Higher Secondary School, Samtse, Bhutan

*Corresponding Author: Nima Dorji, Principal, Khandothang Primary School, Samtse, Bhutan
Received: October 19, 2021

Published: November 17, 2021

(C) All rights are reserved by Nima Dorji and Gembo Rinzin.

\begin{abstract}
When we have a good book to keep a company, there is nothing better in the universe. It takes us to places where we can't go, and lets us meet people we can't meet. Reading is love in action. Nourishing a love of reading in students can be an insuperable task for everyone, but with the perfect use of correct methods, we can easily turn our child into a good reader. Reading is one of the most basic skills students require to learn to be successful. It is not just an essential professional skill, but it is also a way to enjoy creative, informative, and inspiring works of literature that enrich our life experiences. Though reading is the backbone of education, many students are into using computer games and watching television most of the time. Some studies have also shown that many students spent huge amount of time before a screen and we really need to address this problem. Therefore, the purpose of this study is to find out what kind of factors and learning environment encourages or discourages students from reading books and also to explore their present reading habits. It is also aimed to help grade four students develop keen interest in reading with joy and fun through some recommended reading strategies which ultimately will boost their academic performances.
\end{abstract}

Keywords: Nourishing; Professional Skill; Education; Academic Performance

\section{Introduction}

Reading is a complex cognitive process of decoding symbols in order to construct or derive meaning. It is also a complex interaction between the text and the reader resulting in comprehension.

Well success in school is very closely tied to success in reading. It is a common saying that a child learns to read and then reads to learn. "The Education of a child is incomplete if a child is not having the ability to read, to interpret and to understand properly the contents of a reading. As such reading is an essential part of language instruction at every level because it supports learning in multiple ways.

Over the last several years, there has been a general feeling in the Bhutanese society especially in the education circle that the standard of English in Bhutan has declined or is on the decline. To me one possible reason for the decline could be the poor reading habit among our children. This has been the concern for many teachers, educators and parents.

Generally speaking reading habits in Bhutan is relatively poor as compared with other developing nations. Be it in school or home, we hardly read. Even at home how many of us as parents encourage our children to read? Children along with parents are seen glued to the television screen most of the time at home. There is no activity such as reading. Another variable to the issue was that a majority of Bhutanese children come from a non-reading socio-cultural environment. As such they lack guidance and access to reading materials. In school reading focuses on academic purpose only and there are not many books available for pleasure and the only reading 
materials are the text book, reading enjoyable books of personal choice is limited.

Through my teaching experience, I have observed that overcrowded school curriculum, limited and poor library facilities, absence of reading habit among teachers, shortage of trained librarians, lack of sufficient and appropriate reading materials, failure of teachers to create interest among students, inaccessibility of reading materials to the students and poor reading methods were recognized and being pointed out as some major hurdles.

I have also observed that usually children coming from urban areas tend to have a better command over reading than the ones from the rural areas. It might be because for children in rural areas the reading is limited only to school hours. That is why I feel children from rural areas are poor in reading and lack reading habit, as is the case in my school.

\section{Statement of the problem}

Due to poor reading habits, many students perform below expectation in tests and examination. To be an excellent performer, there is need for an individual to make reading a daily habit. But, if we look at today's scenario there is huge influence of mass media. Many do not care about reading a book, magazine or a journal.

In addition modern technological invention and innovation have also contributed a lot in dwindling reading habits in majority of individuals. Many students prefer to watch movies, play online games, and watch movies and TV shows. Parents and teachers also complain about students of our generation not doing well in their studies and always performing worst in everything. They even think that modern gadgets like computers and smart phones are more attractive to the students than books.

According to [1], technology kills reading activities time of children. This means that unnecessary use of modern technology reduces time for reading books in the new generation; this is an issue that needs to be understood by parents, teachers and other stakeholders in education to develop effective reading habits in children in order to facilitate them to improve their academic achievements.

\section{Literature Review}

As a teacher I would like to make reading experiences meaningful, enjoyable and comfortable as possible. In order to create this kind of environment, teacher has to continuously try to understand students learning pathways I am concerned what kind of learning environment encourages or discourages students from reading books. In this chapter, I explore the opinions of other researchers about developing and improving reading habits in children.

\section{Reading}

Reading helps individuals learn how to create sense not only of the world around them but also people, building social-emotional skills and of course, imagination. "Reading exposes all to other styles, other voices, other forms, and other genres of writing. It is regarded as one of the most effective processes of conscious learning. According to Devarajan and Gray, as cited in [2], reading influences the extent and accuracy of information as well as the attitudes, morals, beliefs, judgments and action of readers. These authors postulate that "a creative and pragmatic education involves the habit of personal investigation, which requires self study to be followed by self thinking and analysis".

[3], notes that reading keeps us updated with information and knowledge about everything in the world. He claims that reading has a positive effect on students' academic reading because reading develops their learning skills, enriches their vocabulary and expands their general knowledge. In addition, reading boosts the student's sense of self-esteem and self-efficacy which is why students should comply with reading and make it a daily activity.

It has been asserted that a child can know much about his environment, only, by exposing him or her to reading books, newspapers and magazines. As the child is exposed to reading and develops the love for books, he finds it easier to explore the wealth of human experiences and knowledge. During childhood, it is possible that children miss the opportunity of getting in touch with books and find it difficult to form reading habit at the later years.

\section{Reading habits}

According to [4], "The term reading habit refers to the behavior which expresses the likeness of reading of individual types of reading, and tastes of reading".

Gaining the habit of reading is very important in increasing the rate of reading. In increasing the habit of reading in a society, gaining the habit of reading from a very young age is stressed and the fact that reading habit should be supported starting from early 
childhood is emphasized. It is emphasized that with the development of technology in recent years there has been a drop in children's habit of reading and that television, cell phone, computer games, videos and other technological innovations influence the rate of reading negatively.

[4], put it "the reading habit is best formed at a young impressionable age in school, but once formed, it can last one's life". These authors went on further to say that "children missing the opportunity of getting in touch with books at this stage, find it difficult to acquire reading habits in their later years". Many authors including [1], asserted the notion that reading is a multifaceted cognitive process of building meaning of the texts written in different sources. However, it depends on the ways readers are exposed to the textual attraction for their interest that would not only improve academic performance, but also enable them to become successful in this knowledge society.

\section{Lack of appropriate reading materials}

According to one of the [5], major findings, "The availability of books is the key factor in reading development' only if children are instructed how to use the books. Although it is obvious that having a book rich environment has the positive effect on children's reading, studies have shown that what matter most is what is done with the books. [5] says that as having, a piano in the room will not necessarily make a child a pianist and similarly having books available is no sufficient for the development of highly motivated readers. On the other hand, as pianist needs a piano to perform, there should be high quality books and other reading materials for children to become good readers.

An important factor in developing reading for pleasure is choice. [5] found that when children were asked which book they had enjoyed most, $80 \%$ of them said that the one they had enjoyed most was the one they had chosen themselves. [6] also says that having access to and use of a wide range of self-selected materials are associated with acquisition of vocabulary and comprehension skill in addition to development of reading habit. Indeed [7], pointed out that for pupils to be encouraged to read they should be allowed to choose the books they would like to read, to read books with lots of pictures in them, to read for contests, to have a classroom library and to have an author read to them at school. Once pupils were exposed to different practices of reading and reading materials, they were likely to broaden their imagination and engage in the practice of regular reading.

\section{Lack of modeling}

Modeling refers to the patterning of thoughts, beliefs, strategies, and actions after those displayed by one or more models-usually teachers or parents who explain and demonstrate skills [8]. The role of the teacher is paramount. Research suggests that the frequency with which students read in and out of school depends upon the priority classroom teachers give to independent reading.

Not only is teacher modeling important in itself, it proves to be even more important to low achieving readers. Few of such readers have reading models outside of schools [8]. Therefore, there is greater need for these students to have appropriate reading role models in schools. [9] showed that the gains made by the lowachieving readers under concurrent modeling were greater than those made by the high-achieving readers. But interestingly, many teachers fail to present the lesson with enthusiasm thus defeating the purpose of performing better by the students

\section{Lack of motivation}

Most reading is done in schools and in the schools it is for academic purpose only. There is no proper motivation given to children to reading. The only reading for pleasure is once or twice in a month. Many researchers and teachers, in particular voiced motivation, as their top priority. A leading researcher [10], defines readers who are highly motivated as those who 'generate their own literacy learning opportunities and in so doing they begin to determine their own destiny as literacy learners.' He agrees that reading motivation as the main components of engagement and says that motivated readers will look for meaning, have enjoyment in learning and trust their own reading abilities. Therefore, from the above point of view motivation is seen as an important part for development of reading habits.

Studies also revealed that teachers rewarded pupils who had performed even moderately well in reading with small tokens like sweets or biscuits. Some of the ways in which teachers rewarded their pupils were through showing off the pupils" books to their fellow pupils, asking pupils to read in front of the class and putting stars in the pupil's exercise books. Such rewards encouraged pupils to indulge more in reading since they anticipated being rewarded. 


\section{Research question}

The main question guiding this paper was: How can I improve reading habit of my fourth grade students? In order to focus the study this general question was broken into sub-questions:

- What are the reading habits of Class four children of Khandothang Primary School?

- How many hours do the class four children engage in reading per day?

- What are the sources of reading materials children wholly depend on?

- What are the major factors hindering children from reading?

The above four question are mainly to collect information about children's reading habits. Based on the data and information collected through questionnaires, intervention program to improve reading habit of children of class four was developed and carried out.

\section{Methodology}

Recognizing that biases inherent in any single method could be significantly neutralized by mixed methods [11], this study uses both quantitative and qualitative methods. Quantitative was used because the study intends to collect data from the children that can be analyzed in terms of numbers. While qualitative is used because some information cannot be expressed in number.

The main data collection tools were observation, questionnaires, interview and checklist. Questionnaires were developed as per the relevancy of the learners. The questionnaires included both open and close-ended questions. Respondents were also made to select from two options provided. Data collected was analyzed using simple frequency count and chart. The evidences that I gathered was further crosschecked and compared, to elicit and validate the information.

\section{Procedure}

During the first two week, base line data on children's reading habits was collected using questionnaires. Each child in the class was provided with questionnaires and informed children about the questionnaires and assured them that there is no right and wrong answer and their response will be kept confidential.
Data analysis

Data collected on this study were analyzed using simple frequency count.

\section{Results, Discussion and Conclusion}

The results of the analysis are presented in the following table.

Question 1. What are the reading habits of Class four children of Khandothang Primary School?

Children's reading habits.

\begin{tabular}{|l|c|c|c|}
\hline Sl. No & Items & Yes & No \\
\hline 1 & Do you usually read on a daily basis? & 00 & 33 \\
\hline 2 & Do you read at home? & 33 & 00 \\
\hline 3 & Do you prefer play to reading? & 20 & 13 \\
\hline 4 & Do you prefer watching TV to reading & 26 & 07 \\
\hline
\end{tabular}

Table a

The result shows that class four children do not consider reading as daily routine. This is evident with the response that all the 33 participants responded that they do not read on a daily basic. However, all the participants responded that they read at home. It was also indicated that 20 out of 33 children prefer playing to reading while 26 prefer watching TV to reading.

It is clear from the result that class four children do not have good reading habit and a culture of reading.

Question 2: How many hours do children engage in reading per day?

Hour spent on reading daily.

\begin{tabular}{|c|c|}
\hline $\begin{array}{c}\text { Time/ } \\
\text { Hour Spent Per day }\end{array}$ & Response \\
\hline Less than an Hour & 14 \\
\hline 1-2 Hours & 06 \\
\hline 2- 3 Hours & 08 \\
\hline 3 - 4 Hours & 04 \\
\hline More than 4 Hours & 01 \\
\hline
\end{tabular}

Table b 


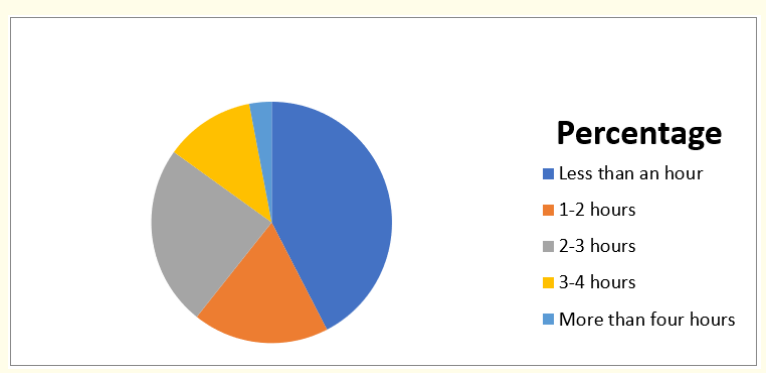

Figure 1: Hour spent on reading.

The result and the figure reveal that 14 children out of 33 that are $42.4 \%$ spent less than an hour on reading per day. While $18.3 \%$ spent between $1-2$ hours, $24.2 \%$ that is 4 children spent $3-4$ hours and only 1 child spent more than 5 hours per day.

From the graph, it is clear that the reading habit of children of class four is not encouraging since there are more children that read less than an hour per day.

Question 3: What are the sources of reading materials children wholly depend on?

Sources of reading materials depend on by the children.

\begin{tabular}{|l|c|c|}
\hline Sl. No & Sources & Responses \\
\hline 1 & Library & 33 \\
\hline 2 & Teacher & 32 \\
\hline 3 & Parents & 10 \\
\hline 4 & Friends & 27 \\
\hline 5 & Others & 08 \\
\hline
\end{tabular}

Table c

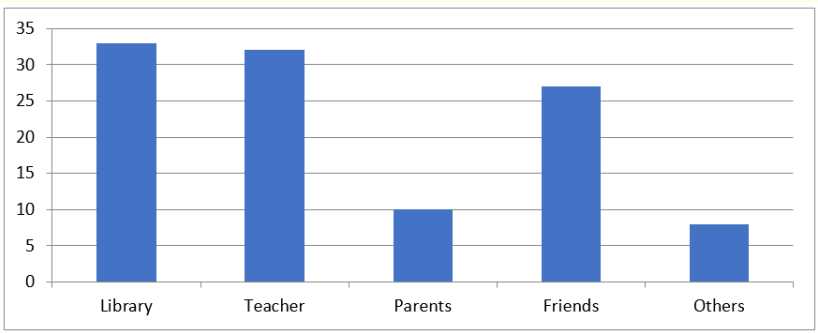

Figure 2: Sources of Reading Materials Depend on by the Children.
Library and teachers are the main source of reading materials children wholly depend on. The children indicated the friends as the next source of reading materials. This is may be because they share their library books with their friends. While 10 students say that they depend on parents, 8 students use other means of reading materials.

Question 4: What are the major factors hindering children from reading?

Hindrance to reading.

\begin{tabular}{|l|c|c|c|}
\hline Sl. No & Hindrances & Responses & Percentage \\
\hline 1 & Playing games & 15 & 45.4 \\
\hline 2 & Watching TV & 10 & 30.3 \\
\hline 3 & Home work & 03 & 9 \\
\hline 4 & $\begin{array}{c}\text { Inadequate books avail- } \\
\text { ability }\end{array}$ & 20 & 60.6 \\
\hline 5 & $\begin{array}{c}\text { Lack of interesting ma- } \\
\text { terials }\end{array}$ & 25 & 75.7 \\
\hline
\end{tabular}

Table d

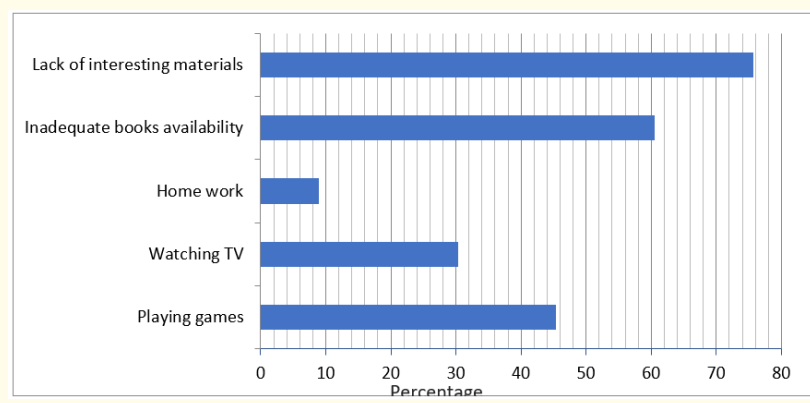

Figure 3

\section{Hindrance to reading}

The result shows that among the factors indicated as hindrance to children's reading habit, lack of interesting materials was rated higher with 25 of the participants. This is followed by inadequate books availability with $60.6 \%$ while playing games as the next factor by 15 . Other factors that hindered the children from reading are watching TV $30.3 \%$ and homework $9 \%$.

\section{Summary of finding}

It is clear from the study that reading habits and culture of class four children is not encouraging. Maximum children read less than 
one hour, which is an indication that they do not read at home and the reading is only done in class during language classes.

The reasons for children lack of reading were due to the lack of interesting materials and availability of inadequate books as revealed in the data. It is a concern for the school and it's important that school library should be equipped with interesting children's literature and story books should be made available in large quantities and that an official hour should be allotted in the day for reading.

\section{Intervention strategies}

After analyzing the data, I observed that the standard and the reading habit of class four children were very poor. To make reading fun, joyful and develop reading habit I selected two of the strategies.

\section{Uninterrupted sustained silent reading (U.S.S.R)}

This is a strategy where all the people in the classroom will be sited and reading books of their choice. The emphasis of U.S.S.R is to provide readers an opportunity to practice reading and built in student the love for reading. The time spent for the reading will be 15 minutes of reading every day during language classes. Teacher will arrange a wide variety of reading materials of varied reading level and interest, so that ever one is easily able to find something he wants to read. The teacher ends the activity while everyone is still working within the frame of U.S.S.R.

\section{Book blast off}

This strategy is followed individually. The teacher makes a chart with the name of all children in the class and display on the wall. Each day a child who had finished reading a book would come in front of the class, share few things about the book, and submit the book review form to the teacher. The teacher adds a star against the child name. The child who gets the maximum star will be rewarded at the end of the intervention programme.

\section{Study procedure}

I chose class four to carry out this research. Considering the findings, first I selected two intervention strategies and then collected all the materials required for the activity. I even developed data collection tools. I started the activity on $7^{\text {th }}$ April 2021, in the class and during school hours with 33 children. Before the activity was carried out, students were briefed on the rules and procedure of the activity. They were also made aware of the activity time, that 15 minutes of the English class shall be kept for the Uninterrupted Sustained Silent Reading activity and the usual class resumes after that. Second activity will be carried out by individual children during their free time. The reading materials were all collected from the library as per the level of the students. Students were given the liberty to choose the reading material of their interest.

\section{Data collection}

The main tools that I have used to collect the data are checklist observation sheet. The observation were made during the first 15 minutes of U.S.S.R reading time and during recess time and other free time as and when I see children reading books. All the observation made was recorded in the journal. Few children were also interviewed to cross check my observation with their opinion and to validate the findings. Checklist was used each day when student who had finished reading book came in front of the class and shared few things about the book, and submits the book review form to the teacher.

\section{Findings}

After one and half month of the intervention programme, I was very impressed by the way, students engaged themselves wholeheartedly in this activity. Every time they are found with a book with the aim to read maximum book and get the reward, every single second was very important for them. Surprisingly, looking at the book blast of chart and the checklist that I have maintained I found that each student in the class could complete reading a minimum of eight books.

It was noticed that students were so keen in the activity that they were found reading during free time, lunchtime and other periods when they were free.

It also improved children confidence, communication and book reviewing skills as each student had to write a book review and share to the class about the book that they have read. Beside the usual interaction between the teacher and the student, it was also observed that students were busy among themselves interacting and sharing about the book they have read. 
The most valuable outcome of this activity is that it aroused the interest of the student and increased their reading time.

I interviewed few children about the activity and found out that the whole approach to improve reading habits was very competitive and fun. Many children also suggested that if reading could be focused using such activities in the class it could arouse interest rather than the compulsory reading where they do not get reading materials of their choice. Some even suggested about the continuity of the activity.

Base on the findings, I strongly feel that we as a teacher we must develop a keen interest in students to read by allowing them to choose the reading materials of their interest, taking them into the world full of fun, joy, and not forcing them to read.

Most reading is done in school and in the schools; it is for academic purpose only. There is no proper motivation given for children to do reading. As such, children do not understand the importance of reading and they do not read. So to develop love for reading, appropriate incentives, teacher praise and intrinsic motivation should be taken into consideration. Since lack of appropriate materials seems to be one of the hindrances to reading, we must develop a keen interest in students to read by providing adequate reading resources and by allowing them to choose books of their interest.

Children must always learn to love reading to develop reading habits. Children need to encounter a wide variety of books that entertain, arouse their interest and excite their curiosity. In many of our schools, there are not many books available of children interest and most of the reading materials are textbooks and readers. Children miss opportunities to read for enjoyment that result in reading impediments. When children's reading skills are under developed and materials are limited, reading becomes difficult and not enjoyable. For the children who live in bookless society, in an oral cultural were reading is thought as work rather than pleasure, teacher needs to think of creating interest among young children with a wide range of books and enjoyable encouraging strategies rather than using pressure to make children read.

Success in bringing up children who will read for pleasure can be fulfilled only when access to book is easy, when children have the choice and time for reading and finally when they are shown the real value of reading.

\section{Appendix A}

Baseline Survey Questionnaires for class IV children

Instructions: Read the statements below and tick $(\sqrt{ })$ under YES or NO.

Children's reading habits.

\begin{tabular}{|l|c|l|l|}
\hline Sl \# & Items & Yes & No \\
\hline 1 & Do you usually read on a daily basis? & & \\
\hline 2 & Do you read at home? & & \\
\hline 3 & Do you prefer play to reading? & & \\
\hline 4 & Do you prefer watching TV to reading & & \\
\hline
\end{tabular}

\section{Table 1}

\section{Appendix B}

Instructions: Read the statements below and tick $(\sqrt{ })$.

Hour spent on reading daily.

\begin{tabular}{|l|l|}
\hline Time/Hour Spent Per day & Response \\
\hline Less than an Hour & \\
\hline 1-2 Hours & \\
\hline 2-3 Hours & \\
\hline 3 - 4 Hours & \\
\hline More than 4 Hours & \\
\hline
\end{tabular}

Table 2

\section{Appendix C}

Instructions: Read the statements below and tick $(\sqrt{ })$.

Sources of reading materials depend on by the children.

\begin{tabular}{|c|c|c|}
\hline Sl\# & Sources & Responses \\
\hline 1 & Library & \\
\hline 2 & Teacher & \\
\hline 3 & Parents & \\
\hline 4 & Friends & \\
\hline 5 & Others & \\
\hline
\end{tabular}

Table 3 


\section{Appendix D}

Instructions: Read the statements below and tick $(\sqrt{ })$ under YES or NO.

Hindrance to reading.

\begin{tabular}{|l|c|l|}
\hline Sl\# & Hindrances & Responses \\
\hline 1 & Playing games & \\
\hline 2 & Watching TV & \\
\hline 3 & Home work & \\
\hline 4 & Inadequate books availability & \\
\hline 5 & Lack of interesting materials & \\
\hline
\end{tabular}

Table 4

\section{Bibliography}

1. Jamila B., et al. "Perception of teachers about the role of parents in developing reading habits". Journal of Educational Development (2018).

2. Panigrahi $\mathrm{C}$ and Panda KC. "Reading interests and information sources of school going children: A case study of two English medium schools of Rourkela, Indian" (1996).

3. Zubidah S and Waleed. "Reading habits and attitudes among students: A Review". Journal of Techno Social 13.1 (2021).

4. Tella A and Akande S. "Children reading habits and availability of books in Botswana primary school: implication for achieving quality education". (2007).

5. Gambrell B and Linda. "Creating classroom cultures that foster reading motivation" (1996).

6. Greaney. "Promoting reading in developing countries" (1996).

7. Gibson J. “Reading for life: The Literacy Guittgenstein” (2004).

8. Jason K. "Teacher Modelling: its impact on an extensive reading program" (2009).

9. Pluck M L., et al. "Teacher and parent modeling of recreational reading". New Zealand Journal of Educational Studies (1984).

10. Guthrie T and John. "Contexts for Engagement and Motivation in Reading” (2001).
11. Creswell J W. "Research Design: Qualitative, Quantitative, and Mixed Methods Approaches". (2003).

\section{Volume 4 Issue 12 December 2021 (c) All rights are reserved by Nima Dorji and Gembo Rinzin.}

